\title{
A. G. GIBSON
}

Alexander George Gibson, who died at Oxford on January 11, 1950, aged 74, was a prominent member of the Cardiac Club. He was chairman of the meeting at Oxford in April, 1922, when it was decided that the club should be founded: John Cowan was the first secretary and Gibson followed him, serving from 1925 to 1928 . He was also chairman of the committee of the Cardiac Society that decided in 1937-38 the time had come to start the British Heart Journal. It is, therefore, particularly fitting that some short record of his life should appear in these pages.

Born at Hull in 1875, Gibson was educated at University College, Aberystwyth, where he read agriculture, and afterwards at Christ Church, Oxford, and at St. Thomas' Hospital, where he held a house appointment. After graduating B.M., he became house-physician to the Radcliffe Infirmary and County Hospital in 1904, and his long association with Oxford remained unbroken from then

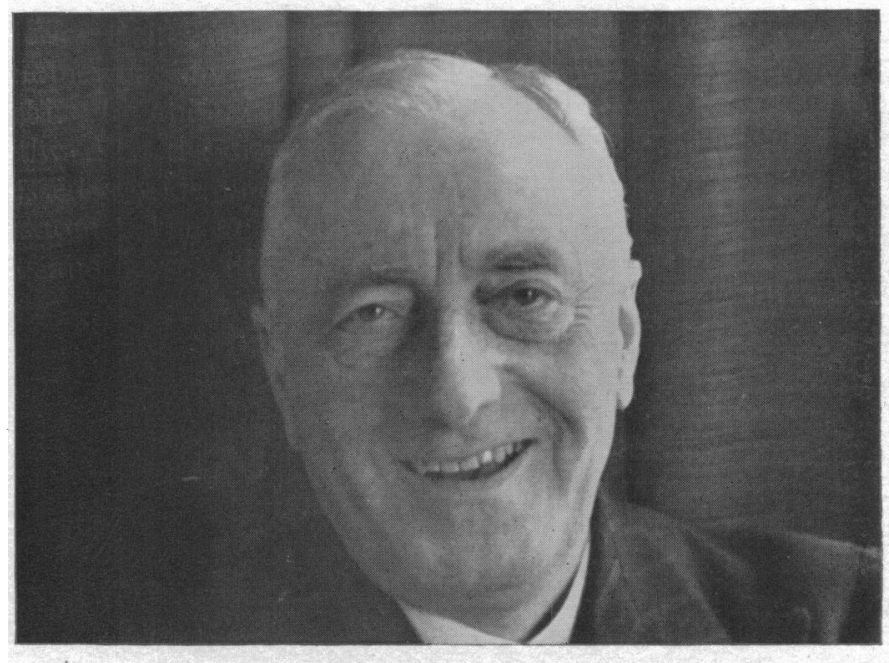

on. He held many posts at the Radcliffe, and helped to raise it to the eminent position that it now holds.

When in 1904 Gibson settled in Oxford he was brought into contact with James Ritchie, reader and later professor of pathology, and with Burdon Sanderson, the regius professor of medicine, whom Osler succeeded the following year. His association with Osler was a particularly happy one, and over the years until Osler's death in 1919 he acquired a certain number of mannerisms from the regius professor, whom, incidentally, he attended in his last illness. It was during these years that he built up his reputation as a pathologist and particularly as a demonstrator of morbid anatomy in the post-mortem room. In 1905 he obtained the M.R.C.P. and in 1908 his D.M: he was elected F.R.C.P. in 1913.

In the early days at Oxford, Gibson had a small general practice in addition to being engaged on pathological teaching and research as University demonstrator at the Museum and as Pathologist to the Radcliffe Infirmary. Later he embarked on consultant practice, becoming particularly interested in cardiology. Both as a family physician and as a consultant, he had the power of 
applying his knowledge with practical success, and his kindness and patience endeared him to his patients. He was quiet and confident in manner and anxiety began to be allayed as soon as he entered the sick-room.

Gibson was appointed physician to the Radcliffe Infirmary in 1919, and was on several occasions Litchfield Lecturer in Medicine and later Nuffield Reader in Pathology. In 1928 he delivered the Bradshaw lecture on pyelitis and pyelonephritis. From 1931 to 1943 he was, in turn, councillor and examiner and censor at the Royal College of Physicians.

There can be few Oxford men who graduated between 1910 and the recent world war who do not owe a great deal to him. He was a good teacher, combining a profound knowledge that ranged widely over clinical and pathological medicine with a clear power of exposition and enthusiasm for seeing that his students understood what he was talking about. His demonstrations of morbid anatomy will be recalled with pleasure by many generations of Oxford men. Clarity of expression was one thing that made them outstanding, and also his careful and accurate correlation of the clinical and post-mortem findings, based on his broad knowledge of these subjects. Though always popular and fond of his students, he was a disciplinarian who knew how to command attention.

He wrote several books. The Radcliffe Infirmary, published in 1926, is a very complete account and is written with affectionate regard for the hospital, its benefactors, and its staff. In 1927 he collaborated with Dr. W. T. Collier in Methods of Clinical Diagnosis, an excellent guide to the subject. In 1930 came The Mycoses of the Spleen; Gibson thought at one time that he had discovered the causative organism of splenic anæmia but this work was not substantiated. Finally, in 1933, a comprehensive series of essays, The Physician's Art: this is perhaps less easy reading than Osler's Counsels and Ideals but few doctors could fail to benefit from its wisdom and common sense, and it shows the high ideals that Gibson set before himself and succeeded in reaching.

Gibson's best known paper, written while he was still young, is his original description of the third heart sound (Lancet, 1907, 2, 1380). Orias and Braun Menedez, in The Heart Sounds in Normal and Pathological Conditions (1939) write as follows:

"The third sound was first described in 1907 by Gibson, whose only means of exploration was simple auscultation. To this author is due not only the credit of its discovery but the much greater merit of having cleanly stated its physiological character and its principal attributes, at a time when the means for observation and study of the heart-sounds were so limited. Referring to his discovery, Gibson wrote: "The sound is by no means easy to hear . . . nor is it possible to hear the sound at every systole; from my own observations it is best heard in the short interval between expiration and inspiration. The quality of the sound is low pitched and clear, with no suspicion of harshness or anything suggesting a murmur. It is slightly increased in intensity and raised in pitch by pressure on the abdomen.'

"Graphical confirmation of the existence of the third sound was obtained very soon after Gibson's publication. Einthoven (1907), at Gibson's suggestion, went over his collection of phonocardiographic records, and in several of them found vibrations appearing some distance after the second sound, that is at the moment referred to by Gibson."

It is true that Gibson called his paper "A hitherto undescribed wave in the jugular pulse " and that it is doubtful whether the sound and the wave really were simultaneous, but this hardly detracts from the merit of his original observation.

Gibson was a member of the Association of Physicians, of the Cardiac Society, and of the Medical Pilgrim's Club. He was Chairman of the Oxford division of the B.M.A. in 1933, and when the Association met at Oxford in 1936, President of the Section of Medicine. He was also a past president of the Oxford Medical Society and helped in founding the Oxford Clinical Club, in which all branches of the local medical profession were represented-general practitioners, research workers, consultants, and specialists in all branches: the fortnightly meetings at 27 Banbury Road were a source of help to all the members and owed much to Gibson.

Gibson regularly attended the meetings of the Cardiac Society, and many friends, especially his old pupils, counted a further talk with him as one of the pleasures of the meeting. He took part in 
many discussions and could be relied upon for his wide knowledge of pathology as applied to the heart-a field that is, perhaps, less well represented among the present members of the Society.

At the 1925 meeting, the discussion on ischæmic necrosis of the heart was opened by Gibson who had collected a good deal of material that helped in the understanding of cardiac infarction, then only recently recognized as a clinical entity that could be diagnosed during life.

Gibson had a long experience of medical journals, as he was the capable and tactful secretary of the editorial board of the Quarterly Journal of Medicine from its foundation in 1907 to 1937, and one of its Editors from 1929-37. It was, therefore, natural that when the question of starting the British Heart Journal was under consideration, his help and advice were of much assistance to the committee that decided in 1937-38 to start this journal.

The last meeting in which he took part was at Oxford in 1941; he was chairman and helped in many ways to make it a great success; he arranged an interesting exhibition of old medical books from the Merton College Library. When the Society met again at Oxford in 1946 he was, unfortunately, too ill to attend.

In addition to his work and his teaching and writing, Gibson was fond of growing flowers, and when ever possible, spent the Sunday afternoon in his garden. He was interested in many aspects of nature and also in genealogy and was a keen member of the Genealogical Society.

Gibson was never quite the same after the tragic death of his wife in 1942, and for the last five years of his life was confined to bed following a cerebral hæmorrhage. He remained cheerful and serene and was fortunate in the devoted services of his daughter. He leaves two sons also, both members of the medical profession.

MAURICE CAMPBELL 